\title{
Analysis of Longitudinal Relationship among Elementary and Middle School Students' Multicultural Acceptance, Self-concept, and Community Consciousness using the Latent Growth Model
}

Choi Eun-Ju', Lee Kyung-Hwab

$\begin{array}{ll}\text { Received } & : \text { 10 January } 2021 \\ \text { Revised } & : \text { 8 February } 2021 \\ \text { Accepted } & : \text { 24 February } 2021 \\ \text { DOI } & \text { 10.26822/iejee.2021.212 } \\ \text { aFirst Author: Choi Eun-Ju, Soongsil University, } \\ \text { Graduate doctoral student } \\ \text { E-mail: cej820220@naver.com } \\ \text { ORCID: https://orcid.org/0000-0003-1973-8913 } \\ \text { bCorrespondence Author: Lee Kyung-Hwa, } \\ \text { Soongsil University, Professor } \\ \text { E-mail: khlee@ssu.ac.kr } \\ \text { ORCID: https://orcid.org/0000-0002-8702-4413 }\end{array}$

KURA

Copyright $@$

www.iejee.com

ISSN: 1307-9298

(c) 2021 Published by KURA Education \& Publishing. This is an open access article under the CC BYNC- ND license. (https://creativecommons.org/ licenses/by/4.0/)

\begin{abstract}
As the proportion of multicultural family increases in Korea, there has been an acceleration in the emergence of a multicultural and multiracial society, resulting in more students with different cultural backgrounds in schools. Therefore, it is necessary to achieve harmony and integration among people from various cultures and backgrounds. The purpose of this study was to identify how multicultural acceptability affects self-concept and community consciousness by using longitudinal data collected for elementary and middle school students using a latent growth model, and to confirm the relationship between these variables. As a result of the study, first, it was confirmed that the multicultural acceptance of elementary and middle school students influences the development of self-concept and community consciousness. Second, a positive correlation was found between the three variables of multicultural acceptance, self-concept, and community consciousness. This study has implications for establishing educational measures relating to multicultural acceptance, self-concept, and community consciousness for adolescents, who are at the stage where perceptions and attitudes toward diverse races and different cultures are cultivated.
\end{abstract}

\section{Keywords:}

Elementary and Middle School Students, Multicultural Acceptance, Self-concept, Community Consciousness, Longitudinal Analysis

\section{Introduction}

$\Lambda$ s the proportion of multicultural family increases in Korea, Athere has been an acceleration in the emergence of a multicultural and multiracial society. Accordingly, the number of students enrolled in higher education institutions with diverse cultural backgrounds and nationalities is 


\section{iejee}

increasing every year (Lee, Chung, Jang, Jang, \& Kim, 2017). Therefore, a discriminatory attitude toward multiculturalism will make it difficult to coexist with people from diverse backgrounds and cultures (Yang \& Kyun, 2020). With the recent crisis caused by the COVID-19 pandemic, internationalization has rather regressed, and a new difficulty has arisen in the acceptance of multiculturalism. The number of multicultural households nationwide in Korea is about 353,800 (Korea National Statistical Office, 2019); thus, efforts to harmonize and integrate Koreans and people from various backgrounds are indispensable to a multicultural society (Lee, 2015). Efforts are required to change the perspective, perception, attitude, and values of members of society toward people from various cultural backgrounds (Choi, 2014). This multicultural attitude is a necessary competency for living in a modern society (Kim, Lee, \& Song, 2020)

In the context of schools, an increase in the number of students from different cultures has made it imperative to develop an attitude to accept diverse cultures and backgrounds in school education (Cha \& Mo, 2017). A lack of multicultural acceptance can affect not only students' perception of and behavior toward others and other cultures, but also their own psychological and social well-being; thus, efforts are needed to increase multicultural acceptance in educational situations (Choi \& Kim, 2015).

Multicultural acceptance refers to the level of accepting as members of a society a group of different races and diverse cultural backgrounds along with the change of a multicultural society (Lee et al., 2017). It is an attitude that supports social values in order to accept the change into a multiethnic and multicultural society and to coexist among various ethnic groups and races (Hwang, 2010). From the perspective of multiculturalism, it can be said that multicultural acceptance is a positive attitude toward multiculturalism that acknowledges and respects diverse cultural backgrounds with an open mindset toward other cultures and recognizes migrants as objects of coexistence (Yoon \& Song, 2011).

Multicultural acceptance, a new perception of diversity, is an important quality that children of multicultural families and adolescents who form peer groups in school must possess (Baek \& Jeong, 2017; Park, 2014). This will enable adolescents to create harmonious relationships through acceptance of other people and other cultures and establish their own human view (Yoo, 2007), as well as to develop positive perceptions of different races and diverse cultures (Han, Kim, \& Jeon, 2014). Based on these prior studies, this research intends to define the concept of multicultural acceptance as an unbiased and tolerant attitude toward people from various backgrounds and cultures.
On the other hand, self-concept, which is the whole of self-perception, is related to multicultural acceptance in that it has an effect on individual perception (Jang \& Eo, 2013). Self-concept is a prerequisite for respecting and looking at others positively (Banks, 1975), and research by Yang and Kim (2015) found that people with high self-esteem positively perceive and respect others. As such, individuals can establish selfunderstanding, self-acceptance, and self-identity, and on the basis of this, they can understand others and accept their perspectives (Bak, Kim, \& Bang, 2016). Self-concept can be defined as an individual's perception and assessment of self (Shavelson, Hubner, \& Stanton, 1976). Lee and Kho (2017) defined the overall perception of oneself, including one's abilities, attitudes, and feelings, as self-concept, and because of its multifaceted characteristics, self-concept is also used as a sub-domain in other fields (Lee \& Kim, 2017). Also the environment is having an important influence on the formation of student self-concept (Ramazan \& Çiftçi, 2020). In other words, self-concept is a comprehensive objective evaluation of oneself formed through various experiences and processes (Hong, 2019).

Erickson (1968) suggests that in adolescence, the objective perception of self is expanded and the selfconcept is established through interaction with others in society. Harter and Whitesell (2003) emphasize that the self-concept is formed by recognizing external evaluation of oneself in the complex interactions of society. Lee and Lew (2014) emphasize a positive selfconcept that recognizes oneself as a competent and valuable being, while at the same time empowering one to have strong power within oneself. In other words, by developing a positive ego, it is possible to develop a tolerant attitude toward different cultures and races (Bennett, 2009).

Another major factor influencing multicultural acceptance is community consciousness (Seo, Jo, \& Kim, 2015), which is defined as a sense of belonging that is influenced by each organization in the society and formed in the interactions among members with a sense of influence (Kang \& Jang, 2013).

Community consciousness (Hahn \& Oh, 2013), which represents psychological states such as a sense of belonging, intimacy, homogeneity, and family consciousness felt by members of the community, is related to lifestyle habits and attitudes that are naturally created in the community environment (Chae, 2013). That is, community consciousness is an indicator of how personal and social problems are closely related in today's world and how people think of the community they belong to (Cho \& Kang, 2016). In addition, social contraction of adolescents can be a factor that influences multicultural acceptance, with research showing that adolescents with low social 
contraction indicate positive and high self-esteem (Park \& Yun, 2018).

Interaction in the community from childhood to adolescence is important (McGue, Elkins, Walden, \& lacono, 2005), and adolescence is a period in which a sense of community consciousness develops by forming relationships with peers with different values in school (Yang \& Kyun, 2020). Community consciousness is an important variable that can affect school life, relationships with peers, and satisfaction with life at home during adolescence (Choi \& Moon, 2013). In addition, community consciousness, like multicultural acceptance, is important in various relationships between individuals and their surroundings (Koo, 2015), and being a social and environmental aspect, can affect multicultural acceptance (Yang \& Kyun, 2020). According to Park, H. S. (2014), who considered community consciousness as a sub-concept of global citizenship and studied its association with multicultural acceptance, the sense of community in the first year of middle school makes the level of multicultural acceptance significant in the second year of middle school. Therefore, it is important to recognize the relationship between multicultural acceptance, selfconcept, and community consciousness based on prior research.

As for the age distribution of children of multicultural families in Korea, 9-11 year olds, who are in the upper grades of elementary school, account for 45.8\%, 12-14 year olds in middle school for 24.1\%, 15-17 year olds for $16.4 \%$, and 18 years and older for $13.8 \%$ (Ministry of Gender Equality and Family, 2019). It is important to introduce multicultural acceptance in the elementary school period because adaptation to elementary school life affects the psychological and social development of students (Choi \& Kim, 2015). In other words, the high grade of elementary school is an appropriate time to increase multicultural acceptance (Yang \& Kim, 2015). Thus, a longitudinal study of high school students who have many opportunities to meet people with diverse cultures and different races will be meaningful.

Therefore, the purpose of this study was to clarify how multicultural acceptability affects self-concept and community consciousness by using longitudinal data collected for elementary and middle school students using a latent growth model, and to confirm the relationship between these variables. For this purpose, the research questions to be confirmed in this study are as follows:

Research Question 1. Does multicultural acceptance of elementary and middle school students influence the development of self-concept and community consciousness?

Research Question 2. What is the relationship between multicultural acceptance, self-concept, and community consciousness of elementary and middle school students?

\section{Method}

\section{Research Subjects}

The purpose of this study is to clarify how multicultural acceptance of elementary and middle school students affects self-concept and community consciousness, and to confirm the relationship between these variables. To this end, five-year panel data of the Korean Education Longitudinal Study (KELS) from elementary school 5th grade to middle school $3^{\text {rd }}$ grade was used for the period from 2013 to 2017. The sample panel consisted of 7,324 fifth grade elementary school students. After excluding the missing values, 5,468 students (male: 2,635; female: 2,833 ) were targeted. The distribution of the research subjects is shown in Table 1.

\section{Table 1.}

Distribution of research subjects

\begin{tabular}{crrr}
\hline & & $\begin{array}{r}\text { Frequency } \\
\text { (persons) }\end{array}$ & Ratio (\%) \\
\hline \hline \multirow{3}{*}{ Gender } & Male & 2,635 & $48.2 \%$ \\
& Female & 2,833 & $51.2 \%$ \\
& Total & 5,468 & $100.0 \%$ \\
\hline
\end{tabular}

\section{Measurement Tool}

Multicultural acceptance. To measure multicultural acceptance, 11 items from (KELS, 2019). Grouped into two sub-factors (perception of foreigners and relation with foreigners and multicultural friends) were used. However, in this study, as in the study of Yang and Kyun (2020), only two of the five items of perception of foreigners, a sub-factor of multicultural acceptance, were used. According to the analysis of Kim, Kang, \& Lee (2014), Koreans generally had positive attitudes toward foreigners in Western countries, but showed low acceptance toward foreigners and immigrants from Asian backgrounds. Therefore, Yang and Kyun (2020) judged that the items classified as perceptions of foreigners in KELS (2019) were mixed with items on two levels that showed these different results. In other words, Yang and Kyun (2020) deleted three items that could confuse the "definition of foreigners" because it seemed to focus on the perception of immigrants from Asian multicultural family backgrounds. Yang and Kyun (2020) have selected all five items in "perception of foreigners", and the reliability of scale is .665 (2015), .695 (2016), .700 (2017), on the other hand, the reliability of scale, excluding the ones that were deleted because it was judged that the respondents felt confused due to the definition of foreigners in the item, was .689 (2015) and .723 (2016) and .735 (2017). 


\section{iejee}

Thus, the multicultural acceptance tool in this study comprised a total of eight questions, two about perception of foreigners and six about relation with foreigners and multicultural friends. Each item was rated on a Likert 5-point scale ranging from "not at all (1 point)" to "very much (5 points)," with a higher score indicating higher multicultural acceptance. The reliability of the multicultural acceptance was computed .899 in 2013, 908 in 2014, .907 in 2015, .924 in 2016, 931 in 2017.

Self-concept. For the self-concept tool, questions from KELS (2016) were used. A total of 20 questions, five each for the four factors of self-concept (social, family, physical, and academic self-concept) were included. Each item was rated on a Likert 5-point scale, with higher scores indicating higher self-concept. The reliability of the self-concept was computed .925 in 2013, .929 in 2014, .930 in 2015, .938 in 2016, .938 in 2017.

Community consciousness. For the community consciousness tool, items from KELS (2019) were used. A total of six items were included for analysis. Of these, two questions were about participation consciousness and four about consideration for others. Each item was rated on a Likert 5-point scale, with higher scores indicating higher community consciousness. The reliability of the community consciousness was computed .843 in 2013, .858 in 2014, .839 in 2015, .847 in 2016, 847 in 2017. The composite reliability of the measurement tools used in this study are shown in Table 2.

The results of CFA in the first year in this study are shown in Table 3.
Table 3.

Fitness Indices of the measurement tools

\begin{tabular}{ccccc}
\hline$\chi^{2} / d f$ & CFI & TLI & RMSEA & RMR \\
\hline 13.974 & .930 & .923 & .049 & .031 \\
\hline
\end{tabular}

As shown in Table 3, CFI and TLI were above .90, and RMSEA was .031. Fitness indices shows overall positive results.

\section{Research Model}

In this study, a latent growth model was used to examine the effects of multicultural acceptance of 5,468 students from elementary school 5th grade to middle school 3rd grade on their self-concept and community consciousness. The research model used in this study is shown in Figure 1.

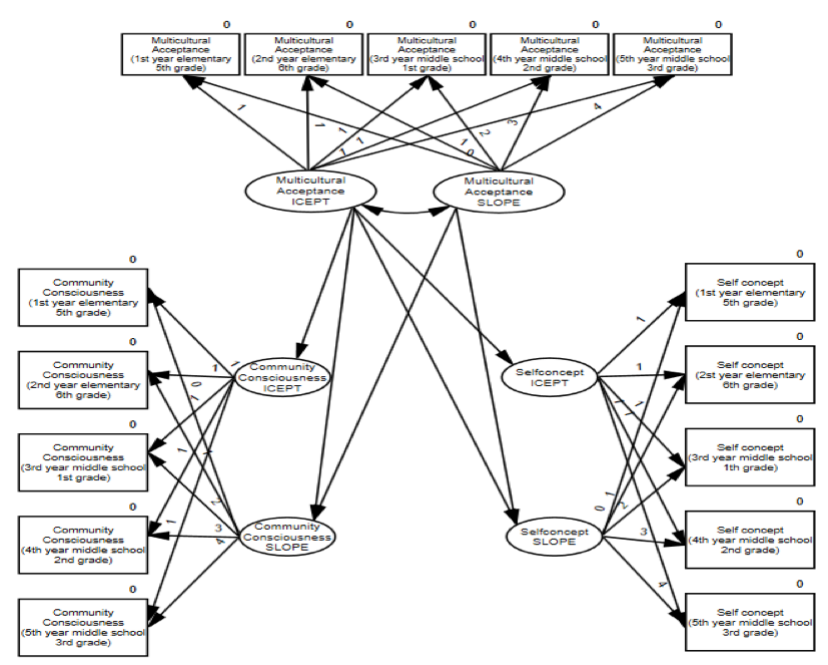

Figure 1.

Research model

Table 2.

Composition and reliability of the measurement tools

\begin{tabular}{|c|c|c|c|c|c|c|c|c|c|c|c|c|}
\hline \multirow{2}{*}{\multicolumn{2}{|c|}{ Variables }} & $\begin{array}{l}\text { Number } \\
\text { of items }\end{array}$ & \multicolumn{10}{|c|}{ Cronbach's $\alpha$} \\
\hline & & \multicolumn{2}{|c|}{$\begin{array}{c}1^{\text {st }} \text { year (ele- } \\
\text { mentary school } \\
5^{\text {th }} \text { grade) }\end{array}$} & \multicolumn{2}{|c|}{$\begin{array}{c}2^{\text {nd }} \text { year } \\
\text { (elementary school } 6^{\text {th }} \text { grade) }\end{array}$} & \multicolumn{2}{|c|}{$\begin{array}{c}3^{\text {rd }} \text { year } \\
\text { (middle } \\
\text { school } 1^{\text {st }} \\
\text { grade) }\end{array}$} & \multicolumn{2}{|c|}{$\begin{array}{l}4^{\text {th }} \text { year } \\
\text { (middle } \\
\text { school } 2^{\text {nd }} \\
\text { grade) } \\
\end{array}$} & \multicolumn{2}{|c|}{$\begin{array}{l}5^{\text {th }} \text { year } \\
\text { (middle } \\
\text { school } 3^{\text {rd }} \\
\text { grade) } \\
\end{array}$} & \\
\hline \multirow[b]{2}{*}{$\begin{array}{l}\text { Multicultural } \\
\text { Acceptance }\end{array}$} & $\begin{array}{c}\text { perception of } \\
\text { foreigners }\end{array}$ & 2 & .732 & \multirow[b]{2}{*}{.899} & .792 & \multirow[b]{2}{*}{.908} & .813 & \multirow[b]{2}{*}{.907} & .843 & \multirow[b]{2}{*}{.924} & .861 & \multirow[b]{2}{*}{.931} \\
\hline & $\begin{array}{c}\text { relation with } \\
\text { foreigners and } \\
\text { multicultural } \\
\text { friends }\end{array}$ & 6 & .911 & & .918 & & .912 & & .930 & & .936 & \\
\hline \multirow{4}{*}{ Self-concept } & society & 5 & .862 & \multirow{4}{*}{.925} & .879 & \multirow{4}{*}{.929} & .894 & \multirow{4}{*}{$.930-$} & .919 & \multirow{4}{*}{-.938} & .924 & \multirow{4}{*}{.938} \\
\hline & family & 5 & .905 & & .920 & & .934 & & .942 & & .948 & \\
\hline & physical & 5 & .861 & & .867 & & .868 & & .875 & & .883 & \\
\hline & Academic & 5 & .874 & & .884 & & .878 & & .897 & & .902 & \\
\hline \multirow{2}{*}{$\begin{array}{l}\text { Community } \\
\text { Consciousness }\end{array}$} & $\begin{array}{c}\text { community } \\
\text { consciousness }\end{array}$ & 2 & .681 & \multirow{2}{*}{\multicolumn{2}{|c|}{.843}} & \multirow{2}{*}{.858} & .678 & \multirow{2}{*}{$.839-$} & .656 & \multirow{2}{*}{-.847} & .636 & \multirow{2}{*}{.847} \\
\hline & $\begin{array}{c}\text { consideration } \\
\text { for others }\end{array}$ & 4 & .814 & & & & .821 & & .835 & & .843 & \\
\hline
\end{tabular}




\section{Analysis Method}

Latent growth model analysis is an analysis method that estimates the magnitude of change at the level of a specific group or individual using longitudinal data measured at least three times through structual equation modeling (SEM) (Kwon \& Lee, 2017). There are observational and latent variables as variables constituting the Latent growth model. The latent variables are composed of the initial value and a rate of change, and the initial value and rate of change are estimated based on the longitudinal data measured each time.

The method and procedure of this study using latent growth modeling is as follows: In this study, the analysis will be performed using the overall score on a multidimensional scales not one by one with the subdimensions. first, in order to check whether the research subject was suitable for the research model, normality of the data was confirmed by reviewing descriptive statistics such as mean, standard deviation, skewness, and kurtosis using SPSS 25.0 program. Then, to examine the latent growth model of variables, the non-change model and the linear change model were measured using AMOS 25.0 program. After comparing the fit, the linear change model of each variable, which showed more appropriate values, was adopted. Finally, the relation between initial value and change rate was verified by synthesizing the linear change model of individual variables and connecting each path.

The full information maximum likelihood (FLML) method was used as the parameter estimation method for the latent growth model. In order to verify the fit of the model, the fit indices comparative fix index (CFI), Tucker-Lewis index (TLI), and root mean square error of approximation (RMSEA) were used (CFI and TLI are .90 or more, RMSEA is .80 or less) (Bentler, 1990; Browne \& Cudeck, 1993; Tucker \& Lewis, 1973).

\section{Results}

\section{Descriptive Statistics Analysis}

Descriptive statistics for the variables of multicultural acceptance, self-concept, and community consciousness used in this study are shown in Table 4. In the case of self-concept, the average decreased from 3.99 to 3.90 from the 1 st to 5 th year. As for community consciousness, as the average increased from 3.83 to 3.94 in the five years, community consciousness also tended to increase. Finally, in the case of multicultural acceptance, the average from 1st to 5 th year ranged from 4.19 to 4.27 , showing a tendency to gradually increase as the year increased. The data in this study has already been proven as public data, and data cleaning has been performed. Therefore, outliers outside the range 1-5 of this scale were identified through descriptive statistics. And there were no outliers, and the analysis was conducted with no missing data.

For all the variables, the absolute value of skewness was less than $2(-0.65$ to -0.06$)$ and that of kurtosis was less than 7 (-0.30 to 0.34), confirming the normality (Kline, 2015).

Table 4.

Descriptive statistics for the variables

\begin{tabular}{|c|c|c|c|c|}
\hline Measure & M & $S D$ & Skewness & Kurtosis \\
\hline \multicolumn{5}{|l|}{ Multicultural Acceptance } \\
\hline (1st year: elementary school & 4.19 & 0.66 & -0.55 & -0.18 \\
\hline \multicolumn{5}{|l|}{$\begin{array}{l}5^{\text {th }} \text { grade) } \\
\text { Multicultural Acceptance }\end{array}$} \\
\hline $\begin{array}{l}\left(2^{\text {nd }} \text { year: elementary }\right. \\
\left.\text { school } 6^{\text {th }} \text { grade }\right) \\
\text { Multicultural Acceptance }\end{array}$ & 4.26 & 0.62 & -0.54 & -0.27 \\
\hline $\begin{array}{l}\text { (3rd year: middle school } 1^{\text {st }} \\
\text { grade) } \\
\text { Multicultural Acceptance }\end{array}$ & 4.13 & 0.58 & -0.40 & -0.23 \\
\hline $\begin{array}{c}\text { (4 } 4^{\text {th }} \text { year: middle school } 2^{\text {nd }} \\
\text { grade) } \\
\text { Multicultural Acceptance }\end{array}$ & 4.23 & 0.62 & -0.48 & -0.12 \\
\hline $\begin{array}{c}\text { (5 year: middle school } 3^{\text {rd }} \\
\text { grade) } \\
\text { Self-concept }\end{array}$ & 4.27 & 0.63 & -0.65 & 0.34 \\
\hline $\begin{array}{c}\text { (15t year: elementary school } \\
5^{\text {th }} \text { grade) } \\
\text { Self-concept }\end{array}$ & 3.99 & 0.58 & -0.54 & 0.28 \\
\hline $\begin{array}{l}\text { (2 }{ }^{\text {nd }} \text { year: elementary } \\
\text { school } 6^{\text {th }} \text { grade) } \\
\text { Self-concept }\end{array}$ & 3.97 & 0.58 & -0.38 & -0.08 \\
\hline $\begin{array}{c}\text { (3rd year: middle school } 1^{\text {st }} \\
\text { grade) } \\
\text { Self-concept }\end{array}$ & 3.95 & 0.58 & -0.22 & -0.24 \\
\hline $\begin{array}{c}\text { ( } 4^{\text {th }} \text { year: middle school } 2^{\text {nd }} \\
\text { grade }) \\
\text { Self-concept }\end{array}$ & 3.92 & 0.61 & -0.21 & -0.17 \\
\hline $\begin{array}{l}\text { (5 } 5^{\text {th }} \text { year: middle school } 3^{\text {rd }} \\
\text { grade) } \\
\text { Community Consciousness }\end{array}$ & 3.90 & 0.63 & -0.19 & -0.12 \\
\hline $\begin{array}{l}\text { ( } 1^{\text {st }} \text { year: elementary school } \\
5^{\text {th }} \text { grade) } \\
\text { Community Consciousness }\end{array}$ & 3.83 & 0.66 & -0.25 & 0.12 \\
\hline $\begin{array}{c}\text { (2 }{ }^{\text {nd }} \text { year: elementary } \\
\text { school } 6^{\text {th }} \text { grade) } \\
\text { Community Consciousness }\end{array}$ & 3.87 & 0.64 & -0.08 & -0.24 \\
\hline $\begin{array}{l}\text { (3rd year: middle school 1 } 1^{\text {st }} \\
\text { grade) } \\
\text { Community Consciousness }\end{array}$ & 3.91 & 0.62 & -0.14 & -0.04 \\
\hline $\begin{array}{l}\text { ( } 4^{\text {th }} \text { year: middle school } 2^{\text {nd }} \\
\text { grade) } \\
\text { Community Consciousness }\end{array}$ & 3.91 & 0.62 & -0.06 & -0.30 \\
\hline $\begin{array}{c}\text { ( } 5^{\text {th }} \text { year: middle school } 3^{\text {rd }} \\
\text { grade })\end{array}$ & 3.94 & 0.63 & -0.21 & -0.08 \\
\hline
\end{tabular}

\section{Correlation between Variables}

The correlation coefficients for the variables used in this study are shown in Appendix. As is evident, selfconcept, community consciousness, and multicultural acceptance showed positive correlations in all areas $(p<.01)$. 


\section{iejee}

\section{Model Verification}

The growth model of self-concept was determined by comparing and reviewing the non-change model and linear change model. Consequently, the linear change model was adopted as it showed a better fit of CFI, TLI, and RMSEA than the non-change model. The initial values for mean and variance of self-concept were $3.996(p<.001)$ and $.225(p<.001)$, respectively, whereas the change rate was -.024 $(p<.001)$ for mean and $.013(p<.001)$ for variance, that is, the mean decreased by .024 every year from the 1st to the 5th year. Further, the initial value and variance of change rate is also statistically significant, indicating that there is an individual difference between the initial value and change rate of self-concept. In the case of community consciousness, the linear change model was found to be good, and hence was adopted. The initial values for mean and variance of community consciousness were $3.845(p<.001)$ and $.245(p<.001)$, respectively, whereas the change rate was .025 ( $p<$ .001) for mean and .013 ( $p$ < .001) for variance. As the mean of the change rate is significant, it can be seen that community consciousness increased by .025 every year from the 1st to the 5th year, and the initial value and variance of change rate is also statistically significant, indicating that there is an individual difference between the initial value and change rate of community consciousness.

As for multicultural acceptance, the linear change model was found to be better than the non-change model in terms of fit indices CFI, TLI, and RMSEA, and hence was adopted. The initial values for mean and variance of multicultural acceptance were 4.213 (p $<.001)$ and $.251(p<.001)$, respectively, whereas the change rate was .021 $(p<.001)$ for mean and .018
( $p=.001)$ for variance. As the mean of the change rate is significant, it can be seen that multicultural acceptance increased by .021 every year from the 1st to the 5th year, which can also be confirmed as statistically significant variance between the initial value and the change rate, indicating that there is an individual difference in the initial value and change rate of multicultural acceptance. Table 5 for model verification is as follows.

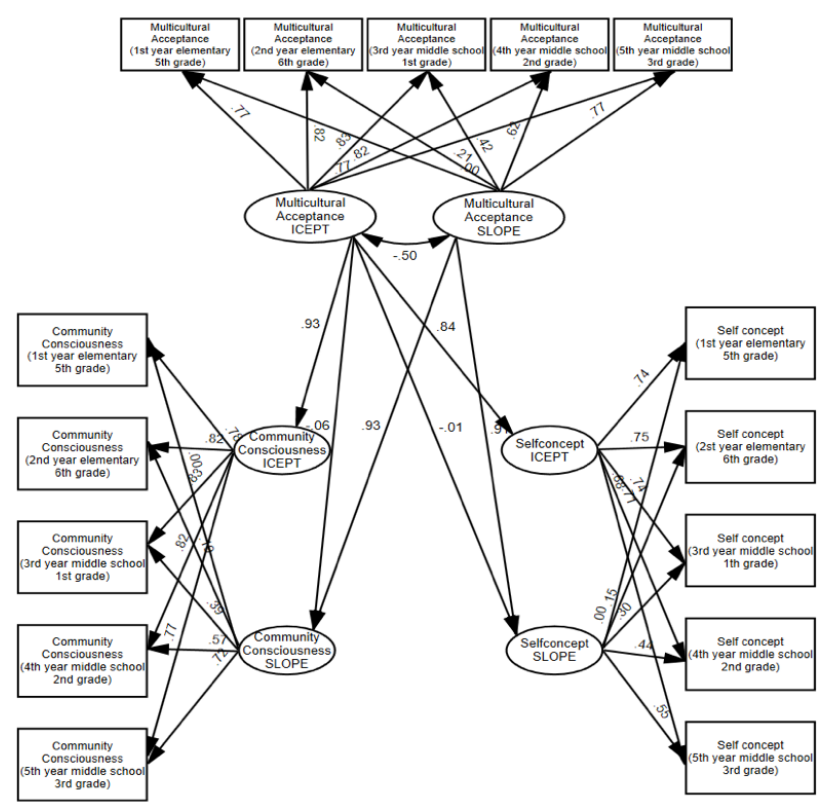

Figure 2.

Causal Model (Standardization coefficient)

Effect of Multicultural Acceptance on Self-concept and Community Consciousness

A multivariate latent growth model was set up by

Table 5.

Model Verification

\begin{tabular}{|c|c|c|c|c|c|c|c|c|c|c|}
\hline \multirow{3}{*}{ variable } & \multirow{3}{*}{ Model } & \multirow{3}{*}{$x^{2}$} & \multirow{3}{*}{$d f$} & \multirow{3}{*}{ CFI } & \multirow{3}{*}{ TLI } & \multirow{3}{*}{ RMSEA } & \multicolumn{3}{|c|}{ Mean } & \multirow{3}{*}{$\begin{array}{r}\text { Variance } \\
\text { change } \\
\text { rate } \\
\end{array}$} \\
\hline & & & & & & & initial & change & initial & \\
\hline & & & & & & & value & rate & value & \\
\hline \multirow{6}{*}{ Self-concept } & non- & & & & & & & & & \\
\hline & change & $1727.933^{\cdots \cdot}$ & 17 & .87 & .92 & .13 & $3.948^{\cdots \cdot}$ & & $201^{\cdots}$ & \\
\hline & model & & & & & & & & & \\
\hline & linear & & & & & & & & & \\
\hline & change & $216.029^{\cdots \cdot}$ & 14 & .98 & .98 & .05 & $3.996^{\cdots \cdot}$ & $-.024^{\cdots \cdot}$ & $.225^{\cdots}$ & $.013^{\cdots}$ \\
\hline & model & & & & & & & & & \\
\hline \multirow{6}{*}{$\begin{array}{l}\text { Community } \\
\text { Consciousness }\end{array}$} & non- & & & & & & & & & \\
\hline & change & $1048.139^{\cdots}$ & 17 & .88 & .93 & .10 & $3.894^{\cdots}$ & & $.186^{\cdots}$ & \\
\hline & model & & & & & & & & & \\
\hline & linear & & & & & & & & & \\
\hline & change & $242.184^{\cdots}$ & 14 & .97 & .98 & .05 & $3.845^{\cdots}$ & $.025^{\cdots}$ & $.245^{\cdots}$ & $.013^{\cdots}$ \\
\hline & model & & & & & & & & & \\
\hline \multirow{5}{*}{$\begin{array}{l}\text { Multicultural } \\
\text { Acceptance }\end{array}$} & non- & & & & & & & & & \\
\hline & change & $1039.131^{\cdots}$ & 17 & .89 & .93 & .11 & $4.238^{\cdots}$ & & $.175^{\cdots}$ & \\
\hline & model & & & & & & & & & \\
\hline & linear & & & & & & & & & \\
\hline & change & $270.196{ }^{\cdots \cdot}$ & 14 & .97 & .98 & .06 & $4.213^{\cdots}$ & $.021^{\cdots}$ & $.251^{\cdots}$ & $.018^{\cdots}$ \\
\hline
\end{tabular}


combining three verified univariate models to reveal how multicultural acceptance of elementary school $5^{\text {th }}$ grade to middle school $3^{\text {rd }}$ students (from the $1^{\text {st }}$ to $5^{\text {th }}$ year) affects their self-concept and community consciousness. The independent variables of the research model are the initial value and change rate of multicultural acceptance, and the dependent variables are the initial value and change rate of selfconcept and community consciousness. The value of the path coefficient of the research model is shown in Table 6.

The initial value of multicultural acceptance was found to have a positive effect on the initial value of community consciousness $(\beta=.929, p<.001)$, and the change rate in multicultural acceptance also had a significant and positive effect on the change rate in community consciousness $(\beta=.932, p<.001)$.

Thus, it can be predicted that the higher the multicultural acceptance rate in the fifth grade of elementary school, the higher the community consciousness; and the higher the rate of increase (= change rate) of multicultural acceptance, the higher the rate of increase (=change rate) of community consciousness (see Figure 3). Further, the initial value of multicultural acceptance had a positive effect on the initial value of self-concept ( $\beta=.763, p<.001)$, and the change rate in multicultural acceptance also had a significant and positive effect on the change rate in self-concept ( $\beta=.913, p<.001)$. Consequently, it can be predicted that $5^{\text {th }}$ grade elementary school students with high multicultural acceptance have a higher self-concept, and a higher rate of increase (= change rate) of multicultural acceptance indicates higher rate of increase (= change rate) of self-concept.

\section{Table 6.}

Value of path coefficient of the research model

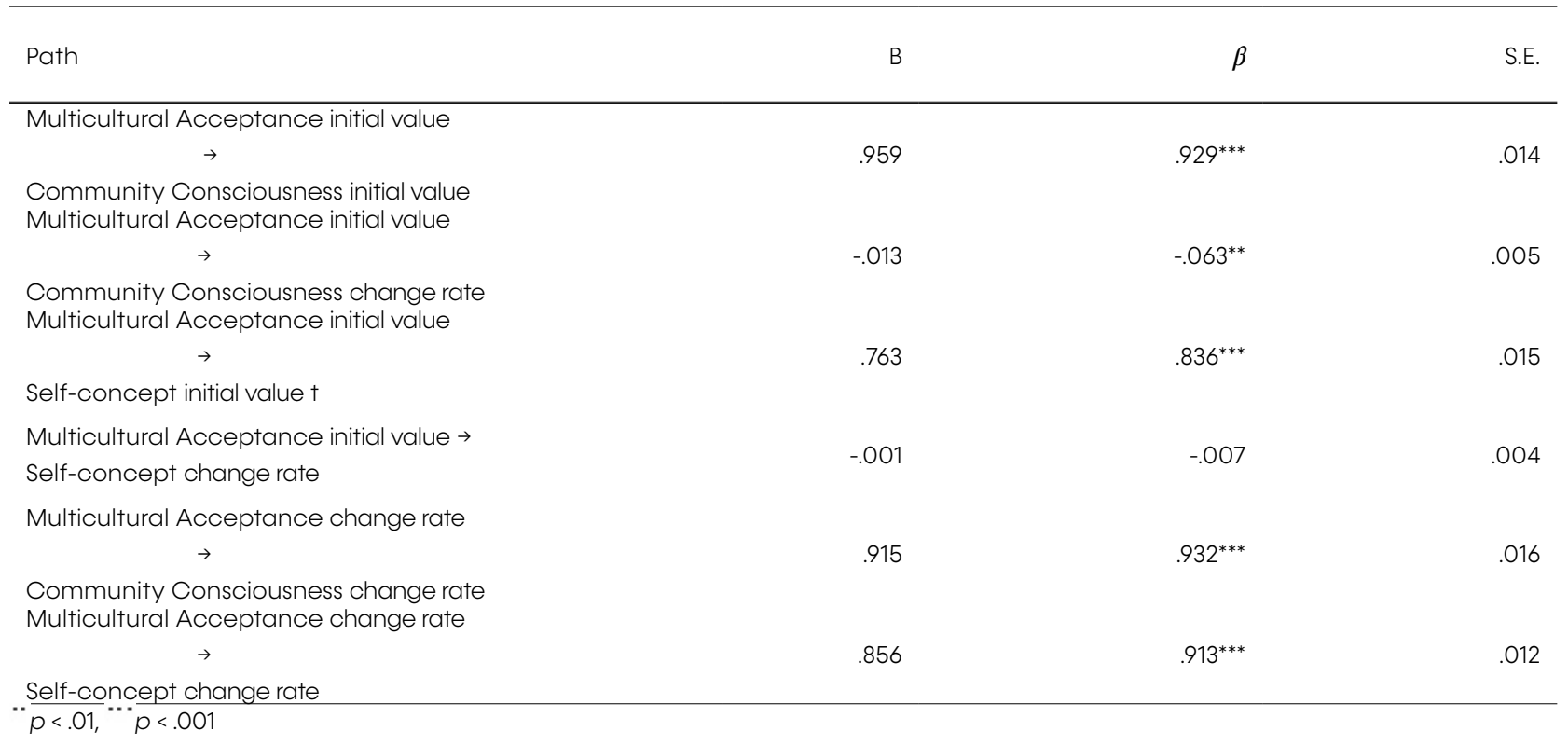




\section{iejee}

the present study suggests that actively cultivating the awareness of and attitude toward others while experiencing various cultures and races in the high grade of elementary school can foster correct perception in the interaction between individuals and society. Lee and Kim (2013) suggested that children who have good relationships with friends, teachers, and neighbors and have developed community consciousness have higher multicultural acceptance, which is consistent with the results of this study.

The findings are also consistent with the research results of Sul, Lee, and Kim (2019), which confirmed that multicultural awareness has a major influence on the self-concept of adolescents, but are somewhat different from those of Lee and Jeon (2014), which confirmed that self-esteem did not directly affect multicultural acceptance. Baek and Jeong (2017) researched middle to high school students and revealed that there were changes in community consciousness depending on the developmental pattern of multicultural acceptance. These results are similar to our findings that individual differences exist between multicultural acceptance, self-concept, and community consciousness. Therefore, it is necessary to adopt a different approach to foster self-concept and community consciousness according to the development pattern of multicultural acceptance.

Second, a positive correlation was found between multicultural acceptance, self-concept, and community consciousness. As with the research results of Choi and Kim (2015), which revealed that community consciousness has a positive effect on multicultural acceptance for elementary school students, this study also confirmed that there is a close relationship between community consciousness and multicultural acceptance. In addition, the research results of Yang and Kyun (2020), which revealed that community consciousness in the first year of middle school has a positive correlation with multicultural acceptance, and Un (2016), which analyzed the factors influencing the multicultural acceptance of adolescents and found that multicultural acceptance increases as community consciousness increases, are in line with the present study, which shows that community consciousness and multicultural receptivity can be connected in a society in which mutual bonds and interactions are established.

According to Jang and Eo (2013), which studied multicultural awareness, there was a high correlation between the personal self, the social self, the academic self, and multicultural acceptance among self-concept. Kim, Cho, and Hong (2020) also showed that adolescents' self-awareness, community consciousness, life satisfaction, and multicultural acceptance were related.
This study reveals the longitudinal effect of multicultural acceptance of elementary and middle school students on self-concept and community consciousness, and has implications for establishing educational measures relating to multicultural acceptance for adolescents, who are at the stage where perceptions and attitudes toward diverse races and different cultures are cultivated. In addition, it was confirmed that multicultural acceptance in adolescence requires effective educational intervention for positive self-concept and community consciousness.

\section{Acknowledgement}

This work was supported by the Ministry of Education of the Republic of Korea and the National Research Foundation of Korea (NRF-2019S1A5C2A04081197)

\section{References}

Baek, S. H., \& Jeong, H. W. (2017). The developmental trajectories of multicultural acceptance and the changing community spirit as determined by means of growth mixture modeling. Studies on Korean Youth, 28(1), 151-182.

Bak, S. W., Kim, J. E., \& Bang, B. N. (2016). A study on the effects to the communication capability and the accommodation of other person's perspective for the self-understanding, the selfaccommodation and the self-communication - Centered on the university students in Gungjido and Seoul -. The Korea Contents Association, 16(7), 410-422.

Banks, J. A. (1975). Teaching strategies for ethnic studies. Allyn and Bacon, Inc., Longwood Division, Rockleigh, New Jersey 07647.

Bennett, C. I. (2009). Comprehensive multicultural education: Theory and practice (Kim et al, Trans.). Seoul: Hakjisa (Original work published in 2007).

Bentler, P. M. (1990). Comparative fit indexes in structural models. Psychological bulletin, 107(2), 238.

Browne, M. W., \& Cudeck, R. (1992). Alternative ways of assessing model fit. Sociological methods \& research, 21(2), 230-258.

Cha, G. S., \& Mo, G. H. (2017). Social studies education. Seoul: Dongmunsa.

Chae, C. W. (2013). The idea of university education and civil educational challenges in the era of globalization. Studies in Humanities and Social Sciences, 39, 5-42. 
Cho, H. U., \& Kang, J. D. (2016). The structural relationship: Over-parenting, adolescents' well-being, community spirit, and school adjustment. Youth Facilities and Environment, 14(2), 139-146.

Choi, M. S. (2014). An analysis of differences and effect factors in multicultural acceptability between teachers and adolescents (Unpublished doctoral dissertation). Donga University.

Choi, J. Y., \& Kim, J. C. (2015). Exploration of psychological and social factors that influence multicultural acceptance for elementary students. Korean Journal of Youth Studies, 22(2), 389-411.

Choi, H. L., \& Moon, Y. K. (2013). Impact of community spirits on school adjustment in adolescents. Journal of Community Welfare, O(45), 189-209.

Erikson, E. H. (1968). Identity: Youth and crisis. New York (WW Norton).

Hahn, D. D., \& Oh, K. H. (2013). The effects of the communal classroom instructional practices and the sense of community on the inhibitory school violence in elementary schools. Korean Journal of Sociology of Education, 23(4), 207235.

Han, Y. S., Kim, B. K., \& Jeon, S. A. (2014). Moderating role of highly-concentrated multicultural neighborhoods in the relationship between individual family factors and multicultural acceptability. Korean Journal of Youth Studies, 21(12), 97-125.

Harter, S., \& Whitesell, N. R. (2003). Beyond the debate: Why some adolescents report stable self-worth over time and situation, whereas others report changes in self-worth. Journal of Personality, 71(6), 1027-1058

Hong, S. K. (2019). Longitudinal relationship of self-concept and civic consciousness for adolescents. The Journal of Learner-Centered Curriculum and Instruction, 19(17), 617-638.

Hwang, J. M. (2010). Analysis of multicultural acceptability in Korea: From the perspective of new politics of membership. The Journal of Asiatic Studies, 53(4), 152-18.

Jang, E. H., \& EO, J. G. (2013). Relationships among children's self-concept, cross-cultural experiences, and multicultural acceptance. Family and Family Therapy, 21(3), 289-305.
Kim, J. W., Kim, M. G., \& Hong, S. H. (2009). Writing thesis with structural equation. Communication books.

Kang, G. Y., \& Jang, Y. M. (2013). A study on the community awareness of youth. Journal of Future Oriented Youth Society, 10(1), 97-123.

Kim, H. J., Cho, M. H., \& Hong, H. Y. (2020). The influence of adolescents' self-awareness on multicultural acceptability: The mediating effect of life satisfaction and sense of community. Korea Youth Research Association, 27(7), 47-76.

Kim, J. D., Lee, E. K., \& Song, S. Y. (2020). Exploring the relationship between multicultural acceptances for global competency development. The Journal of Core Competency Education Research, 5(1), 35-63.

Kim, J. Y., Kang, C. G., \& Lee, U. C. (2014). Closed Korea: Koreans' multicultural perceptions and policies. Seoul: Asan Publications.

Kim, Y. B., Lim, H. J., Namgung, J. Y., Park, H. J., Shin, H. S., Kim, S. S., Kim, J. M., Lee, G. M., \& Bn, J. C. (2013). Korean Education Termination Study (KELS) 2013(I) Survey Summary Report. Jin cheon: Korea Educational Development Institute.

Kline, R. B. (2015). Principles and practice of structural equation modeling. Guilford publications.

Koo, J. H. (2015). The grade difference in community spirit and multicultural acceptability of elementary school students. Theory and Research in Citizenship Education (TRCE), 47(1), $1-24$.

Korea National Statistical Office (KOSTAT). (2019). Census 2015-2019: Multicultural households and household members-City, County. Statistics Office, Korea, Population Census

Korean Education Longitudinal Study (KELS). (2016). Korean Education Logitudinal Study (KELS) 2005(X): Survey Summary Report. Korea Educational Development Institute.

Korean Education Longitudinal Study (KELS). (2019). Korean Education Logitudinal Study (KELS) 2013(VII): Survey Summary Report. Korea Educational Development Institute. 


\section{iejee}

Kwon, S. O., \& Lee, S. Y. (2017). Analysis of longitudinal relations between creativity, academic achievements, and utilization of computer \& smartphone of middle school students. The Korean Association of Computer Education, 20(3), 35-46.

Lee, S. K. (2015). Longitudinal changes and determinants of adolescents' acceptability toward multiculture. Korean Journal of Youth Studies, 22(10), 27-48.

Lee, S. K., \& Jeon, S. M. (2014). Factors that have impacts on the multi-culture acceptance of middle school students: Focused on self-esteem, community closeness, peer attachment. Journal of Adolescent Welfare, 16(4), 103-121.

Lee, J. H., \& Kim, K. K. (2013). Determinants of multicultural acceptability of middle school students. Korean Journal of Sociology of Education, 23(1), 53-77.

Lee, K. H., \& Kim, C. Y. (2017). The effect of on-line creativity class on promotion of creative personality and self-concept. Journal of Education \& Culture, 23(1), 33-64.

Lee, K. H., \& Kho, J. Y. (2017). SCl-Il self-concept test, expert guide. Seoul: INPSY.

Lee, K. H., \& Lew, K. H. (2014). The effect of creativity and personality education on the elementary, middle, and high school students. The Journal of Creativity Education, 14(1), 1-16.

Lee, H. S., Chung, J. Y., Jang, S. Y., Jang, S. H., \& Kim, J. R. (2017). An analysis of factors affecting elementary school students' levels of multicultural acceptance. Studies on Korean Youth, 28(2), 225-248.McGue, M., Elkins, I., Walden, B., \& lacono, W. G. (2005). Perceptions of the parent-adolescent relationship: A longitudinal investigation. Developmental Psychology, 41(6), 971.

Ministry of Gender Equality and Family. (2019). 2018 national multicultural family survey research. Research Report 2019-01.

Park, H. S. (2014). Investigating factors related to multicultural receptivity for elementary and middle school students. Studies in Humanities and Social Sciences, 44, 5-33.

Park, J. H., \& Yun, C. M. (2018). Mediated effect of aggression and adjusted mediating effect of ego resilience in the relationship between adolescents' peer attachment and multicultural
March 2021, Volume 13, Issue 4, 565-576

acceptance. Global Creative Leader: Education \& Learning, 8(4), 63-86.

Park, S. H. (2014). A longitudinal analysis on multicultural perception of young people using latent growth model. Multiculturalism and Human, 3(2), 99-131.

Ramazan, O., \& Çiftçi, H. A. (2020). A Comparison of Turkish and South Korean Preschool Children's Gender Self-Concepts. International Electronic Journal of Elementary Education, 13(1), 107-115.

Seo, B. E., Jo, H. M., \& Kim, M. Y. (2015). A study of factors influencing multicultural acceptance among middle school students in Korea. Culture Technology Research Institute, 19, 179-207.

Shavelson, R. J., Hubner, J. J., \& Stanton, G. C. (1976). Selfconcept: Validation of construct interpretations. Review of Educational Research, 46(3), 407-441.

Sul, J. B., Lee, E. K., \& Kim, J. H. (2019). Multicultural acceptance of natives and self-concept and school achievement of migrant adolescents in Korea - Moderating effect of social support -. Crisisonomy, 15(7), 103-123.

Tucker, L. R., \& Lewis, C. (1973). A reliability coefficient for maximum likelihood factor analysis. Psychometrika, 38(1), 1-10.

Un, S. K. (2016). A study on factors influencing on adolescents' multicultural acceptability: Compared elementary school students and middle school students. Journal of Korea Academia-Industrial Cooperation Society, 17(10), 685-695.

Yang, Y. M., \& Kim, J. S. (2015). Relationship between children's self-esteem, sense of community, and multicultural receptivity. Journal of Youth Welfare, 17(4), 309-328.

Yang, M. H., \& Kyun, S. N. (2020). A longitudinal study on the development of multicultural acceptance of Korean middle school students: Focusing on the variables of self-concept and community consciousness. Institute of Distance Education, 16(1), 79-100.

Yoo, Y. A. (2007). A symbolic interaction study on the impact of peer culture on the ego identity of middle schoolers (Unpublished master's thesis). Inha University.

Yoon, I. J., \& Song, Y. H. (2011). South Koreans' perceptions of national identity and acceptance of multiculturalism. The Korean Journal of Unification Affairs, 23(1), 143-192. 
Korean Education Longitudinal Study (KELS). (2016).

Korean Education Logitudinal Study (KELS) 2005(X): Survey Summary Report. Korea Educational Development Institute.

Korean Education Longitudinal Study (KELS). (2019). Korean Education Logitudinal Study (KELS) 2013(VII): Survey Summary Report. Korea Educational Development Institute.

Kline, R. B. (2015). Principles and practice of structural equation modeling. Guilford publications. 


\section{Appendix}

Correlation between major variables

\begin{tabular}{|c|c|c|c|c|c|c|c|c|c|c|c|c|c|c|c|}
\hline & 1 & 2 & 3 & 4 & 5 & 6 & 7 & 8 & 9 & 10 & 11 & 12 & 13 & 14 & 15 \\
\hline 1 & 1 & & & & & & & & & & & & & & \\
\hline 2 & $.629^{\prime \prime}$ & 1 & & & & & & & & & & & & & \\
\hline 3 & $.523^{\prime \prime}$ & $.640^{\prime \prime}$ & 1 & & & & & & & & & & & & \\
\hline 4 & $.462^{\prime \prime}$ & $.563^{* \prime}$ & $.675^{\prime \prime}$ & 1 & & & & & & & & & & & \\
\hline 5 & $.422^{\prime \prime}$ & $.514^{\prime \prime}$ & $.604^{\prime \prime}$ & $.683^{\prime \prime}$ & 1 & & & & & & & & & & \\
\hline 6 & $.668^{\prime \prime}$ & $.436^{\prime \prime}$ & $.357^{\prime \prime}$ & $.309^{* *}$ & $.275^{\prime \prime}$ & 1 & & & & & & & & & \\
\hline 7 & $.430^{\prime \prime}$ & $.664^{\prime \prime}$ & $.430 "$ & $.376^{\prime \prime}$ & $.332^{\prime \prime}$ & $.513^{\prime \prime}$ & 1 & & & & & & & & \\
\hline 8 & $.348^{\prime \prime}$ & $.441^{\prime \prime}$ & $.620^{\prime \prime}$ & $.448^{\prime \prime}$ & $.391^{\prime \prime}$ & $.420 "$ & $.516^{\prime \prime}$ & 1 & & & & & & & \\
\hline 9 & $.318^{* \prime}$ & $.392^{\prime \prime}$ & $.470^{\prime \prime}$ & $.619^{* \prime}$ & $.473^{\prime \prime}$ & $.375^{\prime \prime}$ & $.444^{\prime \prime}$ & $.563^{* \prime}$ & 1 & & & & & & \\
\hline 10 & $.303^{\prime \prime}$ & $.375^{\prime \prime}$ & $.427^{\prime \prime}$ & $.477^{\prime \prime}$ & $.619^{\prime \prime}$ & $.338^{\prime \prime}$ & .401" & $.496^{\prime \prime}$ & $.580^{\prime \prime}$ & 1 & & & & & \\
\hline 11 & $.474^{\prime \prime}$ & $.320^{\prime \prime}$ & $.260^{\prime \prime}$ & $.222^{\prime \prime}$ & $.197^{\prime \prime}$ & $.575^{\prime \prime}$ & $.402^{* *}$ & $.319^{\prime \prime}$ & $.281^{\prime \prime}$ & .270" & 1 & & & & \\
\hline 12 & $.335^{\prime \prime}$ & $.505^{\prime \prime}$ & $.326^{\prime \prime}$ & $.290^{* *}$ & $.243^{\prime \prime}$ & $.398^{\prime \prime}$ & $.612^{\prime \prime}$ & $.392^{\prime \prime}$ & $.348^{\prime \prime}$ & $.323^{* *}$ & $.532^{* *}$ & 1 & & & \\
\hline 13 & $.274^{\prime \prime}$ & $.347^{\prime \prime}$ & $.489^{\prime \prime}$ & $.340^{\prime \prime}$ & $.299^{\prime \prime}$ & $.320^{\prime \prime}$ & $.388^{\prime \prime}$ & $.591^{\prime \prime}$ & $.413^{\prime \prime}$ & $.376^{\prime \prime}$ & $.430^{\prime \prime}$ & $.512^{\prime \prime}$ & 1 & & \\
\hline 14 & $.245^{\prime \prime}$ & $.283^{\prime \prime}$ & $.336^{\prime \prime}$ & $.454^{\prime \prime}$ & $.326^{\prime \prime}$ & $.296^{\prime \prime}$ & $.324^{\prime \prime}$ & $.396^{\prime \prime}$ & $.582^{\prime \prime}$ & $.420^{\prime \prime}$ & $.382^{\prime *}$ & $.444^{\prime *}$ & $.563^{\prime \prime}$ & 1 & \\
\hline 15 & $.223^{* \prime}$ & $.271^{\prime \prime}$ & $.307^{\prime \prime}$ & $.355^{\prime \prime}$ & $.453^{\prime \prime}$ & $.262^{* \prime}$ & $.300^{*}$ & $.364^{\prime \prime}$ & $.428^{\prime \prime}$ & $.596^{\prime \prime}$ & $.352^{* *}$ & .411" & $.500^{* \prime}$ & $.585^{\prime \prime}$ & 1 \\
\hline
\end{tabular}

$\cdots p<.01$ note: 1 . Self-concept (1 $1^{\text {st }}$ year: elementary school $5^{\text {th }}$ grade), 2. Self-concept ( $2^{\text {nd }}$ year: elementary school $6^{\text {th }}$ grade), 3. Selfconcept ( $3^{\text {rd }}$ year: middle school $1^{\text {st }}$ grade), 4. Self-concept (4th year: middle school $2^{\text {nd }}$ grade), 5. Self-concept ( th $^{\text {th }}$ year: middle school $3^{\text {rd }}$ grade), 6. Community Consciousness (15t year: elementary school $5^{\text {th }}$ grade), 7. Community Consciousness (2nd year: elementary school $6^{\text {th }}$ grade), 8. Community Consciousness ( $3^{\text {rd }}$ year: middle school $1^{\text {st }}$ grade), 9. Community Consciousness ( $4^{\text {th }}$ year: middle school $2^{\text {nd }}$ grade), 10. Community Consciousness ( $5^{\text {th }}$ year: middle school $3^{\text {rd }}$ grade), 11. Multicultural Acceptance (1 $1^{\text {st }}$ year: elementary school $5^{\text {th }}$ grade), 12. Multicultural Acceptance $\left(2^{\text {nd }}\right.$ year: elementary school $6^{\text {th }}$ grade), 13. Multicultural Acceptance ( $3^{\text {rd }}$ year: middle school $1^{\text {st }}$ grade), 14. Multicultural Acceptance ( $4^{\text {th }}$ year: middle school $2^{\text {nd }}$ grade), 15 . Multicultural Acceptance ( $5^{\text {th }}$ year: middle school $3^{\text {rd }}$ grade) 